\title{
Botulinum Toxin for Ocular Tics
}

\author{
Gilad Yahalom ${ }^{1,2^{*}}$, Achinoam Faust-Socher ${ }^{1}$, Hanna Strauss ${ }^{1}$, Sheera F. Lerman ${ }^{1,3}$, Sharon Hassin- \\ Baer $^{1,2}$ and Oren S. Cohen ${ }^{1,2}$
}

\author{
${ }^{I}$ The Parkinson Disease and Movement Disorders Clinic, Sagol Neuroscience Center, Chaim Sheba Medical Center, \\ Tel-Hashomer, Israel \\ ${ }^{2}$ Sackler Faculty of Medicine, Tel-Aviv University, Tel-Aviv, Israel \\ ${ }^{3}$ Department of Psychology, Ben Gurion University of the Negev, Beer Sheva, Israel
}

\begin{abstract}
Introduction: Onabotulinum toxin A is an effective treatment for a variety of movement disorders; yet, results of efficacy in patients with medically-resistant tic disorders are insufficient. We aimed to assess the efficacy of Onabotulinum toxin A in patients with ocular tics in an observational study.

Methods: Patients with ocular tics, regularly treated with Onabotulinum toxin A injections at our clinic, were enrolled for 2 visits, one of which was for baseline assessment and a single injection session and the second -a follow-up visit one month after treatment for evaluation of outcome. The assessment tools consisted of a 10-minute videotape recording which was scored later by a blinded rater. The calculated ocular tic frequency was the primary end-point of this study. Secondary outcome measures consisted of additional items obtained from the video recording as well as the motor subset of the Yale Global Tic Severity Scale (YGTSS-M) and the Clinical Global Impression of change (CGI-C).
\end{abstract}

Results: Six patients were enrolled.Video recordings and rating of the ocular tics before and after treatment revealed a $37 \%$ reduction in mean tic frequency, a 2.18-fold prolongation of the time to the first tic following suppression and a reduction in tic frequency during and after suppression by $45 \%$ and $52 \%$, respectively. The mean YGTSS-M decreased by $39 \%$. Five patients reported an improvement in CGI-C while one reported no change.

Conclusions: In this observational study, Onabotulinum toxin A was found to be an effective treatment for ocular tics, providing both subjective and objective benefit for a subset of patients.

Keywords: Botulinum toxin, efficacy, ocular tics, tic disorder.

\section{INTRODUCTION AND BACKGROUND}

A tic is a semi- or involuntary body movement or vocal sound that is sudden, rapid and repetitive [1]. It has a stereotyped but non-rhythmic character. The tic is preceded usually by a premonitory sensation or "urge" and is experienced as irresistible although it can be suppressed for a short period of time. Tics can be categorized as motor or vocal and as simple or complex [1].

Tics involving the eyelids or ocular muscles (ocular tics) are among the most common forms of motor tics. They may be part of transient or chronic tic disorders or part of Tourette syndrome (TS). The pathophysiology of tics is still not clear. Basal ganglia dysfunction was postulated as the main site of dysfunction while recent evidences indicate cerebellar involvement in tic generation [2].

Although some medications such as dopamine depletors, neuroleptics, benzodiazepines and alpha2-agonists are in use

*Address correspondence to this author at the Department of Neurology, Sheba Medical Center, Tel Hashomer 52621, Israel; Tel: 972-3-5303643; Fax: 972-3-5305323; E-mail: gyahalom@gmail.com for tics relief, the efficacy of these medications is still questionable and the treatment is often limited by severe side effects including sedation, parkinsonism, tardive dyskinesia, hepatotoxicity and prolongation of QT-interval [3], that make their use in non-TS tic disorders unjustified.

Onabotulinum toxin $\mathrm{A}$ is a potent neurotoxin that blocks neuromuscular transmission and when injected to the affected muscles, it is effective for a variety of movement disorders including dystonia [4] and spasticity [5]. Its efficacy in tic disorders was assessed in a small number of studies [6-9], which showed in most cases a beneficial effect.

In the present observational prospective study, we aimed to document both objective and subjective effects of Onabotulinum toxin A injections for ocular tics.

\section{MATERIALS AND METHODS}

Between the years 2010- 2012, patients diagnosed by a movement disorder specialist at Sheba Medical Center as having ocular tics, and who were treated regularly by Onabotulinum toxin A, were enrolled. All patients had failed on various oral therapies. The study was approved by the 
institutional review board and all patients signed an informed consent form prior to inclusion.

All patients had 2 visits: A baseline visit (visit 1), in which demographics and medical records were reviewed and Onabotulinum toxin A injection was administered; and a follow-up visit (visit 2) one month after treatment. The injected muscles included the orbicularis oculi (upper and lower eyelids), frontalis, corrugators and paranasal muscles and the exact sites and the doses were adjusted on an individual basis, depending on the location, the description and extent of the tics. The injection sites and doses were usually identical to the patient's prior injection sessions, as these had been found previously to provide the best effect.

\section{Efficacy Evaluation}

In both visits patients had a 10-minute videotape recording of the face, including 5 minutes of baseline or neutral state, 3 minutes of voluntary attempt of tic suppression, and 2 minutes neutral state following suppression. The video recordings were assessed in a random order by a single rater (OC) blinded to the visit, for number of tics during rest period, and during and following suppression. In addition, the time to first tic following suppression was documented. The tic frequency during rest obtained from these recordings was the primary end-point of this study. Additionally, patients completed the motor subset of the Yale Global Tic Severity Scale (YGTSS-M). At visit 2, patients were asked to rate the Clinical Global Impression of Change (CGI-C) questionnaire and were inquired about side effects of the injections.

\section{Statistical Analysis}

Due to the small sample size, statistical analysis was not performed. Instead, we measured the proportional change in the outcome of the different scores at visit 2 versus baseline, as follows:

Proportional change $=\frac{\text { outcome visit } 2 \quad \text { outcome at visit } 1}{\text { outcome visit } 1}$

\section{RESULTS}

Six patients were enrolled (3 males, age \pm SD: $40.5 \pm$ 15.3 years) and treated by injections of Onabotulinum toxin A to the muscles surrounding the eyes. Three patients had an isolated ocular tic disorder, 2 had mild TS, 1 patient suffered from tardive tics, and 1 patient had both cervical and ocular tics.

The mean total dose of Onabotulinum toxin A (Botox ${ }^{\circledR}$; Allergan Pharmaceuticals, Irvine, California, USA) was $40.17 \pm 11.2 \mathrm{IU}$ (range 29-60 IU). The mean number of previous Onabotulinum toxin A treatment sessions prior to enrollment was $7.5 \pm 3.2$.

Measures of the ocular tics are presented in Table 1. The mean tic frequency during rest was averagely reduced by $37 \%$. In addition the tic frequency decreased both during and after suppression by $45 \%$ and $52 \%$, respectively, and the time to the first tic during suppression was prolonged by 2.18-fold. The YGTSS-M score was reduced by $39 \%$ (5 patients improved). Five patients reported an improvement on CGI-C while one reported no change.

\section{DISCUSSION}

In this small observational study of patients with ocular tics treated with Onabotulinum toxin A injections, a clinically significant objective and subjective benefit was evident as both reduction of tics frequency along with patient satisfaction were documented.

Table 1. Rating of Ocular Tics before and after treatment with Botulinum toxin injections.

\begin{tabular}{|c|c|c|c|c|c|c|c|c|c|c|c|c|c|c|c|c|c|}
\hline \multirow[t]{2}{*}{ Pt. } & \multirow[t]{2}{*}{$\begin{array}{l}\text { Gen } \\
\text { der/ } \\
\text { Age } \\
\text { (yea } \\
\text { rs) }\end{array}$} & \multicolumn{2}{|c|}{$\begin{array}{c}\text { Tic frequency } \\
\text {-rest- } \\
\text { (blinks/sec) }\end{array}$} & \multirow[t]{2}{*}{ 总 } & \multicolumn{2}{|c|}{$\begin{array}{c}\text { Time to } \\
\text { first tic } \\
\text {-suppression- } \\
\text { (sec) }\end{array}$} & \multirow[t]{2}{*}{ 题 } & \multicolumn{2}{|c|}{$\begin{array}{l}\text { Tic frequency } \\
\text { - suppression- } \\
\text { (blinks/sec) }\end{array}$} & \multirow[t]{2}{*}{ 总 } & \multicolumn{2}{|c|}{$\begin{array}{l}\text { Tic frequency } \\
\text {-after } \\
\text { suppression } \\
\text {-(blinks/sec) }\end{array}$} & \multirow[t]{2}{*}{ 总 } & \multicolumn{2}{|c|}{ YGTSS-M } & \multirow[t]{2}{*}{$\begin{array}{l}\text { 影 } \\
\text { 恶 }\end{array}$} & \multirow[t]{2}{*}{$\begin{array}{l}\text { CGI- } \\
\text { CPt }\end{array}$} \\
\hline & & Pre & Post & & Pre & Post & & Pre & Post & & Pre & Post & & Pre & Post & & \\
\hline 1 & $\mathrm{~F} / 47$ & 4.0 & 0.6 & 0.85 & 8 & 109 & 12.63 & 3.0 & 1.3 & 0.57 & 12.5 & 1.5 & 0.88 & 13 & 9 & 0.31 & $+1+$ \\
\hline 2 & $\mathrm{~F} / 49$ & 3.2 & 1.8 & 0.44 & 76 & 40 & 0.47 & 1.7 & 2.7 & 1.59 & 7.5 & 1.0 & 0.87 & 9 & 9 & 0 & - \\
\hline 3 & $\mathrm{~F} / 22$ & 4.8 & 6.2 & 1.29 & 13 & 22 & 1.69 & 3.0 & 1.3 & 0.57 & 11 & 10.5 & 0.05 & 11 & 9 & 0.18 & + \\
\hline 4 & $\mathrm{M} / 25$ & 4.4 & 3.0 & 0.32 & 10 & 62 & 5.20 & 4.3 & 1.3 & 0.70 & 5.5 & 4.5 & 0.18 & 10 & 7 & 0.30 & $+1+$ \\
\hline $5^{*}$ & $\mathrm{M} / 38$ & 43.4 & 5.2 & 0.88 & & & & & & & & & & 10 & 0 & 1 & ++ \\
\hline $6^{*}$ & M/62 & 53.8 & 25.4 & 0.53 & & & & & & & & & & 21 & 11 & 0.48 & +++ \\
\hline $\begin{array}{l}\text { Mean } \\
\pm \text { SD }\end{array}$ & & $\begin{array}{c}19.6 \pm \\
24.5\end{array}$ & $\begin{array}{c}7.0 \pm \\
9.2\end{array}$ & 0.37 & $\begin{array}{c}26.8 \pm \\
32.9\end{array}$ & $\begin{array}{c}58.3 \pm \\
37.6\end{array}$ & 2.18 & $3.0 \pm 1.1$ & $\begin{array}{c}1.6 \pm \\
0.7\end{array}$ & 0.45 & $\begin{array}{c}9.1 \pm \\
3.2\end{array}$ & $\begin{array}{c}4.4 \pm \\
4.4\end{array}$ & 0.52 & $\begin{array}{c}12.3 \pm \\
4.5\end{array}$ & $\begin{array}{c}7.5 \pm \\
3.9\end{array}$ & 0.39 & \\
\hline
\end{tabular}

Abbreviation: Pt - patient; Pre - before treatment; Post - after treatment; YGTSS-M - Motor subscale of the Yale Global Tic Severity Scale; CGI-C - The Change in Clinical Global Improvement Scale, rated by the patient; - no change, + mild improvement, ++ moderate improvement, +++ very much improved.

*Patients who were only videotaped in rest (neutral state) due to technical problems. 
Our positive results are in accordance with previous reports of treatment of various tics in patients with diverse tic disorders; Kwak et al. [6] assessed 35 patients (14 of whom had ocular tics) in an open label study and the patients favorably rated the treatment with Onabotulinum toxin A using a 0-4 simple scale, with a mean peak effect of 2.8. The study of Kwak et al. did not rate the different tics separately, thus the specific effect on ocular tics was lacking.

Marras et al. [7] conducted a randomized placebocontrolled study of Onabotulinum toxin A versus placebo injections including 18 patients with simple motor tics (10 of whom had ocular tics). Treatment response items were retrieved from videotape recording as well as several additional scales and the primary outcome measure was tic frequency during rest from the video recording. While Onabotulinum toxin A was effective in tic rate reduction (39\% in treated patients vs. $5.8 \%$ increase in tics in the placebo group), it did not have a favorable effect on the patient general well-being, as expressed by the CGI-C patient questionnaire, the Shapiro Tourette Syndrome Severity Score and other scores, probably due to the impact of the remaining tics not targeted by the injections. The study of Marras et al. neither rated the different tics separately, thus the specific effect on ocular tics was lacking.

Patients included in our report were those complaining of one bothersome focal tic, involving the ocular area, for which they were seeking an effective treatment. Our sample could potentially be biased since it consists of those patients who were treated routinely, and were supposed to be satisfied from the treatment. None of our patients was naïve to Onabotulinum toxin A treatment. There is lack of information on the proportion of patients lost to follow up due to treatment failure.

We do not know what portion of patients with ocular tics may benefit from Onabotulinum toxin A injections and what the profile of responders is. This will have to be studied in a large group of Onabotulinum toxin A treatment-naïve subjects suffering from ocular tics in a randomized doubleblind placebo-controlled study.

Nevertheless we have shown that a subset of these patients gain both an objective and a subjective improvement of their tics with this treatment. Others have shown that the premonitory urge decreases as well with these injections $[6$, 8].

\section{CONCLUSION}

As we are convinced that Onabotulinum toxin A injections are effective for ocular tics, and their safety profile is excellent in the hands of experienced physicians, this conservative focal treatment should be offered in the case of bothersome ocular tics possibly prior to offering oral medication, as the latter option commonly provides both limited efficacy and frequent side effects.

\section{CONFLICT OF INTEREST}

The authors confirm that this article content has no conflict of interest.

\section{ACKNOWLEDGEMENTS}

Declared none.

\section{REFERENCES}

[1] Rampello L, Alvano A, Battaglia G, Bruno V, Raffaele R, Nicoletti F. Tic disorders: from pathophysiology to treatment. J Neurol 2006; 253(1): 1-15.

[2] McCairn KW, Iriki A, Isoda M. Global dysrhythmia of cerebrobasal ganglia-cerebellar networks underlies motor tics following striatal disinhibition. J Neurosci 2013; 33(2): 697-708.

[3] Hansen TE, Casey DE, Hoffman WF. Neuroleptic intolerance. Schizophr Bull 1997; 23(4): 567-82.

[4] Ramirez-Castaneda J, Jankovic J. Long-term efficacy and safety of botulinum toxin injections in dystonia. Toxins (Basel) 2013; 5(2): 249-66.

[5] Ghasemi M, Salari M, Khorvash F, Shaygannejad V. A literature review on the efficacy and safety of botulinum toxin: an injection in post-stroke spasticity. Int J Prev Med 2013; 4 (Suppl 2): S14758 .

[6] Kwak CH, Hanna PA, Jankovic J. Botulinum toxin in the treatment of tics. Arch Neurol 2000; 57(8): 1190-3.

[7] Marras C, Andrews D, Sime E, Lang AE. Botulinum toxin for simple motor tics: a randomized, double-blind, controlled clinical trial. Neurology 2001; 56(5): 605-10.

[8] Jankovic J. Botulinum toxin in the treatment of dystonic tics. Mov Disord 1994; 9(3): 347-9.

[9] Rath JJ, Tavy DL, Wertenbroek AA, van Woerkom TC, de Bruijn SF. Botulinum toxin type A in simple motor tics: short-term and long-term treatment-effects. Parkinsonism Relat Disord 2010; 16(7): 478-81.

Received: January 06, 2015

Revised: April 10, 2015

Accepted: April; 14, 2015

(C) Yahalom et al.; Licensee Bentham Open.

This is an open access article licensed under the terms of the Creative Commons Attribution Non-Commercial License (http://creativecommons.org/licenses/by-nc/3.0/) which permits unrestricted, non-commercial use, distribution and reproduction in any medium, provided the work is properly cited. 